\title{
Effect of Low Bi Content on Reliability of Sn-Bi Alloy Joints Before and After Thermal Aging
}

\author{
HIROSHI NISHIKAWA @i), ${ }^{1,4}$ YUKI HIRATA, ${ }^{1,2}$ CHIH-HAN YANG,${ }^{3}$ \\ and SHIH-KANG LIN ${ }^{3}$

\begin{abstract}
1.-Joining and Welding Research Institute, Osaka University, 11-1 Mihogaoka, Ibaraki, Osaka, Japan. 2.-Graduate School of Engineering, Osaka University, 2-1 Yamadaoka, Suita, Osaka, Japan. 3.-Department of Materials Science and Engineering, National Cheng Kung University, 1 University Rd, Tainan City 701, Tainan, Taiwan. 4.—e-mail: nisikawa@jwri.osakau.ac.jp
\end{abstract}

$\mathrm{Sn}-58 \mathrm{Bi}$, an eutectic alloy, has been explored for use as a low-temperature lead-free solder alloy. However, the properties of $\mathrm{Sn}-\mathrm{Bi}$ alloys as well as those of their joints need to be improved significantly so that these alloys can be applicable for practical use. In particular, two drawbacks need to be addressed: the intrinsic brittleness of $\mathrm{Bi}$ and the microstructure coarsening of these alloys during aging. In this study, Sn-Bi-Zn (SBZ) and SBZ-In (SBZI) alloys with low $\mathrm{Bi}$ contents were examined to elucidate the effects of the addition of $\mathrm{Zn}$ and $\mathrm{In}$ to the $\mathrm{Sn}-45 \mathrm{Bi}$ alloy on the interface and shear strengths of $\mathrm{Cu} / \mathrm{Cu}$ joints before and after aging. In the case of the SBZ/Cu and SBZI/Cu joints, Bi coarsening was not observed either near or at the interfaces of the $\mathrm{Cu} / \mathrm{Cu}$ joints. The shear strengths of the SBZ and SBZI joints remained unchanged after aging for $1008 \mathrm{~h}$, suggesting that the SBZI alloy demonstrated the highest long-term reliability among all the joints examined.

\section{INTRODUCTION}

Over the past few decades, owing to the implementation of the RoHS directive and the increased environmental consciousness of consumers, leadfree solder alloys have been developed for use as alternatives to eutectic $\mathrm{Sn}-\mathrm{Pb}$ solders. ${ }^{1,2} \mathrm{Sn}-\mathrm{Ag}$ and $\mathrm{Sn}-\mathrm{Ag}-\mathrm{Cu}$ solders, such as $\mathrm{Sn}-3.5 \mathrm{Ag}$ and $\mathrm{Sn}-3.0 \mathrm{Ag}-$ $0.5 \mathrm{Cu}$, are considered the most promising lead-free systems for both conventional wave and reflow soldering processes in the electronics industry. ${ }^{3}$ In addition, lead-free solder alloys based on Sn-based systems have been continuously investigated. Recently, smart functional materials for wearable, bendable, and flexible electronics are trending and thus have become an area of active research in the field of electronics. ${ }^{4,5}$ Interconnect materials in electronics should not only be capable of adapting to the mechanical and electrical connections but also be able to withstand the rapid and low-

(Received October 7, 2021; accepted December 26, 2021; published online February 1, 2022) temperature process. ${ }^{6}$ High soldering temperatures required for $\mathrm{Sn}-\mathrm{Ag}$-Cu solders may result in thermal warpage and cause damage on the electronics devices fabricated using smart functional materials. Therefore, printable, fine-pitch-capable, and lowtemperature-processable interconnect materials are desirable for electronics. Accordingly, the electronic assembly industry is gradually adopting low-temperature soldering, and the demand for low-temperature lead-free solder alloys has increased significantly in the electronics industry. Low-temperature lead-free solder alloys can also be expected to reduce the amount of energy consumed during the assembly process.

The most suitable low-temperature alloys are Sn$\mathrm{Zn}$ and Sn-Bi alloys, which are chemically and metallurgically different to a significant extent from the conventional $\mathrm{Sn}-\mathrm{Ag}-\mathrm{Cu}$ solders. ${ }^{7,8}$ However, the presence of $\mathrm{Zn}$ results in low corrosion resistance, ${ }^{9}$ and highly active fluxes are required to remove the $\mathrm{Zn}$ oxide formed during processing. Therefore, eutectic Sn-58Bi (SB) alloy has been explored for use as low-temperature lead-free solder alloys. ${ }^{10}$ The melting temperature of the eutectic Sn-Bi alloy 
is $139^{\circ} \mathrm{C}$; this alloy exhibits good joint strength, creep resistance, and wettability. In the eutectic composition, a lamellar structure is observed, wherein the Sn-rich phase and $\mathrm{Bi}$ phase form continuous networks. However, the eutectic Sn-Bi alloy has two significant limitations that need to be addressed: the intrinsic brittleness of $\mathrm{Bi}$ and the microstructural coarsening of the alloy during aging. ${ }^{11,12}$ The formation of an approximately 3 mass\% $\mathrm{Bi}$ solid solution in the $\mathrm{Sn}$ phase significantly increases the hardness because of solid solution hardening, ${ }^{13}$ thereby decreasing the ductility of the alloy.

To improve the properties of solder alloys and interfacial reactions at the interface, trace amounts of specific elements such as In, $\mathrm{Ni}$, and Co have been added to the alloys, and the effect of these elements on alloy properties have been explored. ${ }^{14-16}$ Choi et al. investigated the effects of the addition of In on the properties of a binary eutectic Sn-3.5mass\%Ag solder. The microstructure of the solder and morphologies of the secondary phases in the solder matrix changed with the addition of In. ${ }^{14}$ In addition, Anderson showed that Co addition to the Sn$\mathrm{Ag}-\mathrm{Cu}$ solder results in microstructural refinement and improves the solder's ability to maintain its shear strength after aging. ${ }^{15}$ Non-metal reinforcement doping is another method for improving the performance of lead-free solders. ${ }^{17-20}$ For example, $\mathrm{Xu}$ et al. ${ }^{17}$ reported the addition of graphene nanosheets can effectively suppress the growth of intermetallic compounds (IMCs) at the interface between $\mathrm{Sn}-\mathrm{Ag}-\mathrm{Cu}$ solder and $\mathrm{Cu}$ substrates.

Several studies have investigated the effects of the addition of trace amounts of $\mathrm{Ag}$, In, $\mathrm{Cu}_{6} \mathrm{Sn}_{5}$ particles, and carbon nanotubes on the properties of the eutectic Sn-Bi alloy. ${ }^{21-23}$ In a previous study, we investigated the effects of the addition of different elements on the properties of Sn-Bi alloys with the aim of improving their properties. ${ }^{24-26}$ The In atoms segregated at the grain boundaries between the Sn phase and $\mathrm{Bi}$ phases, and the grain coarsening of the Bi phase was suppressed. In addition, the solid solution formed in the $\mathrm{Sn}$ phase counteracts the strengthening effect of the Bi solution. As a result, the addition of In to the eutectic SB alloy increased its elongation. ${ }^{24}$ The presence of trace amounts of $\mathrm{Zn}$ effectively refined the microstructure of the eutectic SB alloy and improved its mechanical properties such as elongation and tensile strength. ${ }^{25}$ In addition, to improve its mechanical properties of the $\mathrm{Sn}-\mathrm{Bi}$ alloy, we varied the $\mathrm{Bi}$ content in the alloy from $58 \%$ to $45 \mathrm{Bi}^{27,28} \mathrm{In}$ the $\mathrm{Sn}$ $45 \mathrm{Bi}-2.6 \mathrm{Zn}$ alloy, an extremely fine microstructure and Sn-Bi-Zn (SBZ) ternary structure were observed, and the volume fraction of the Sn-rich phase was higher than that of the eutectic SB alloy. A $112 \%$ increase in the elongation of the Sn-45Bi$2.6 \mathrm{Zn}$ alloy was observed and was attributable to the increased Sn-to-Bi volume ratio. ${ }^{27}$ The effects of the addition of $\mathrm{Zn}$ and In on the microstructure and mechanical properties of Sn-Bi alloys have also been investigated to further improve the properties of these alloys. ${ }^{28}$ However, the interfacial reactions and strengths of SBZ-In (IBZI) joints have not been investigated in detail. The reliability of these joint during aging must be examined. In this study, the applicability of $\mathrm{Cu} / \mathrm{Cu}$ joints formed using a $\mathrm{Sn}-45 \mathrm{Bi}$ alloy adding $\mathrm{Zn}$ and In as solders were investigated. The study was performed with the aim of elucidating the effects of the addition of $\mathrm{Zn}$ and In to the Sn$45 \mathrm{Bi}$ alloy on the joint interfaces and shear strengths of the $\mathrm{Cu} / \mathrm{Cu}$ joints formed using these alloys before and after aging.

\section{EXPERIMENTAL}

A Zn wire (99.99 mass\%, Niraco), In sheet (99.99 mass\%, Niraco), and Sn sheet (99.99 mass\%, Niraco) were alloyed with a commercial eutectic Sn-58 mass\%Bi alloy (SB) (Nihon Genma Mfg. Co., Ltd., Japan) to manufacture the Sn-45 mass\%Bi-2.6 mass\%Zn (SBZ) and Sn-45 mass\%Bi-2.6 mass\%Zn0.5 mass\%In (SBZI) alloys. For the alloying process, the metals were heated and melted in a $\mathrm{N}_{2}$ atmosphere at $700{ }^{\circ} \mathrm{C}$ for $5 \mathrm{~h}$, after which the molten alloys were cast in a bar-shaped mold. Table I lists the chemical compositions of the alloys prepared in this study. The thermal properties of the fabricated alloys were measured by differential scanning calorimetry (DSC, DSC7020, Hitachi High-Tech Co., Japan).

The alloys were rolled into foils with a thickness of $100 \pm 10 \mu \mathrm{m}$ using a rolling machine and punched into samples with a diameter of 3 or $5 \mathrm{~mm}$. Before being heated, the alloy foils and the $\mathrm{Cu}$ substrates were cleaned with an $\mathrm{HCl}$ solution $(4 \mathrm{vol} \%)$ and ethanol. An oxygen-free $\mathrm{Cu}$ plate was used as the substrate to prepare the wettability test samples, as shown in Fig. 1a. An alloy foil with a diameter of 3 mm was coated with a flux (no. 67, Nihon Genma Mfg. Co., Ltd., Japan) on either sides and placed at the center of the $\mathrm{Cu}$ plate. Subsequently, to form a joint sample, as shown in Fig $1 \mathrm{~b}$, oxygen-free $\mathrm{Cu}$ disks with diameters of 5 and $10 \mathrm{~mm}$ were used as the upper and bottom substrates, respectively. Before forming the joint sample, the $\mathrm{Cu}$ disks were polished with \#2000 SiC grit paper and a $1.0 \mu \mathrm{m}$ diamond slurry (DP-spray P, Struer, USA). Subsequently, both the alloy foils and $\mathrm{Cu}$ disks were cleaned thoroughly. The alloy foil was coated with flux on both sides and placed in the middle of the two $\mathrm{Cu}$ disks to form the joint samples. The samples were preheated at $100{ }^{\circ} \mathrm{C}$ for $60 \mathrm{~s}$ and reflowed at $160{ }^{\circ} \mathrm{C}$ for $180 \mathrm{~s}$ in a $\mathrm{N}_{2}$ atmosphere; the oxygen concentration in the furnace during the entire reflow process was maintained at $100 \mathrm{ppm}$, and the measured profile is shown in Fig. 2. Figure 1c and $d$ shows the wettability test samples and the joint samples, respectively, after the reflow process. 
Table I. Chemical compositions of alloys investigated in this study

\begin{tabular}{|c|c|c|c|c|c|c|c|c|c|c|c|c|c|c|}
\hline \multirow[b]{2}{*}{ Alloy } & \multicolumn{14}{|c|}{ Composition (mass\%) } \\
\hline & Sn & $\mathbf{B i}$ & $\mathbf{Z n}$ & In & $\mathbf{P b}$ & Ag & $\mathbf{S b}$ & $\mathbf{C u}$ & $\mathbf{F e}$ & Al & As & $\mathbf{C d}$ & $\mathbf{N i}$ & $\mathbf{A u}$ \\
\hline Sn-45Bi (SB) & 42.08 & Balance & 0.00 & 0.006 & 0.001 & 0.001 & 0.003 & 0.000 & 0.000 & 0.000 & 0.001 & 0.000 & 0.001 & 0.000 \\
\hline $\begin{array}{l}\text { Sn-45Bi-2.6Zn } \\
\text { (SBZ) }\end{array}$ & 52.37 & Balance & 2.49 & 0.008 & 0.003 & 0.001 & 0.003 & 0.001 & 0.000 & 0.000 & 0.000 & 0.000 & 0.001 & 0.000 \\
\hline $\begin{array}{l}\text { Sn-45Bi-2.6Zn- } \\
0.5 \mathrm{In}(\mathrm{SBZI})\end{array}$ & 53.98 & Balance & 2.53 & 0.499 & 0.000 & 0.001 & 0.003 & 0.001 & 0.000 & 0.000 & 0.001 & 0.000 & 0.001 & 0.000 \\
\hline
\end{tabular}

(a)

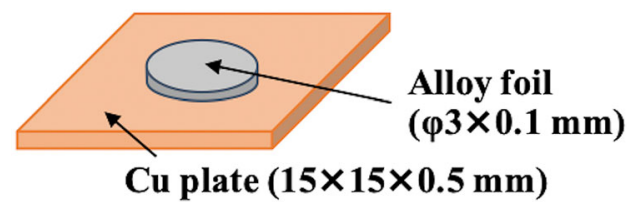

(b)

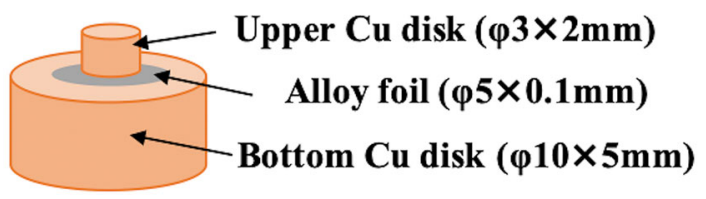

(c)

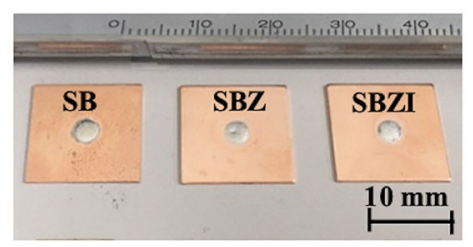

(d)

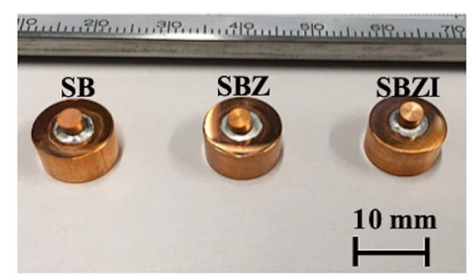

Fig. 1. Images of $\mathrm{Cu} / \mathrm{alloy} / \mathrm{Cu}$ sample. (a) Schematic illustration of wettability test sample, (b) schematic illustration of joint sample, (c) photographs of wettability test sample after reflow process, and (d) photographs of joint sample after reflow process.

Finally, both types of test samples were subjected to solid-state thermal aging in an oil bath at $80^{\circ} \mathrm{C}$ for 504 and $1000 \mathrm{~h}$.

To evaluate the wettability of the alloys on the $\mathrm{Cu}$ substrate, the contact angle formed at the interface between the alloy in question and the substrate was measured using a three-dimensional laser scanning confocal microscope (VK-9710, Keyence Co., Japan). Field-emission scanning electron microscope (FESEM, SU-70, Hitachi High-Tech Co., Japan) in combination with energy dispersive x-ray spectroscopy (EDS) was conducted to observe the microstructure and interfacial layer of the wettability test sample. The thickness of the IMC layer at

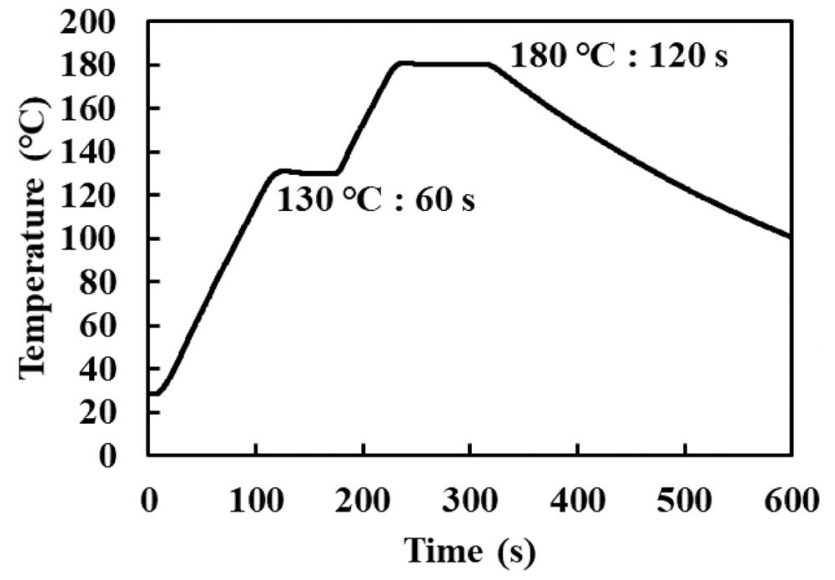

Fig. 2. Measured reflow profile for joint sample.

the interface between the alloy and the $\mathrm{Cu}$ substrate was measured from the SEM images using the quantitative analysis software ImageJ. FE-SEM was also conducted to observe the fracture surface of the bottom $\mathrm{Cu}$ disk after the shear test. Then, the void ratio was calculated by dividing the void area by the joint area.

A shear test machine (STR-1000, Rhesca Co., Ltd., Japan) was used to determine the shear strengths of the jointed samples; the tests were performed at a cross-head speed of $1 \mathrm{~mm} / \mathrm{min}$ at room temperature $\left(25{ }^{\circ} \mathrm{C}\right)$, and the height of the shear tool was $300 \mu \mathrm{m}$ from the surface of the bottom $\mathrm{Cu}$ substrate. The detailed schematic of the shear test is shown in Fig 3. The shear strength was calculated by dividing the maximum shear force by the joint area. We prepared four samples for each alloy, conducted the shear test in the same condition, and then calculated the average value of four samples regarding it as the shear strength of each alloy.

\section{RESULTS AND DISCUSSION}

\section{Characteristics of As-cast Alloys}

The melting behavior is a basic and important thermal property of low-temperature solder alloys. The DSC analysis was conducted, and the heating step during the DSC analysis was performed at a 
heating rate of $10^{\circ} \mathrm{C} / \mathrm{min}$ to investigate the melting behavior of each alloy. Figure 4 shows DSC curves of the eutectic SB, SBZ, and SBZI alloys. The onset temperature $\left(T_{\mathrm{s}}\right)$ and offset temperature $\left(T_{\mathrm{L}}\right)$ of the alloys were obtained from the curves and are listed in Table II. The $T_{\mathrm{s}}$ values of alloys SBZ and SBZI are lower than that of the alloy SB. In addition, the $T_{\mathrm{L}}$ values of alloys SBZ and SBZI are lower than that of the alloy SB. Moreover, the $T_{\mathrm{s}}$ and $T_{\mathrm{L}}$ values are in the range of $130-140{ }^{\circ} \mathrm{C}$, and this temperature range is suitable for low-temperature solder alloys.

The equilibrium contact angle was determined by balancing the surface tensions as per Young's equation, which assumes an ideal surface under a thermodynamic equilibrium. However, the wetting behavior of molten alloys involves the flow of the molten alloy on the surface of the substrate. This flow is affected by factors such as the viscosity of the molten alloy and the reaction between the alloy and the substrate. A smaller contact angle indicates better wettability. For the contact angle measurement, we prepared four samples for each alloy and measured the contact angle of samples at room temperature after reflow heating. Then, we got the average value and regarded it as the standard contact angle. Figure 5 shows the contact angles of the three types of alloys on the $\mathrm{Cu}$ substrate. The

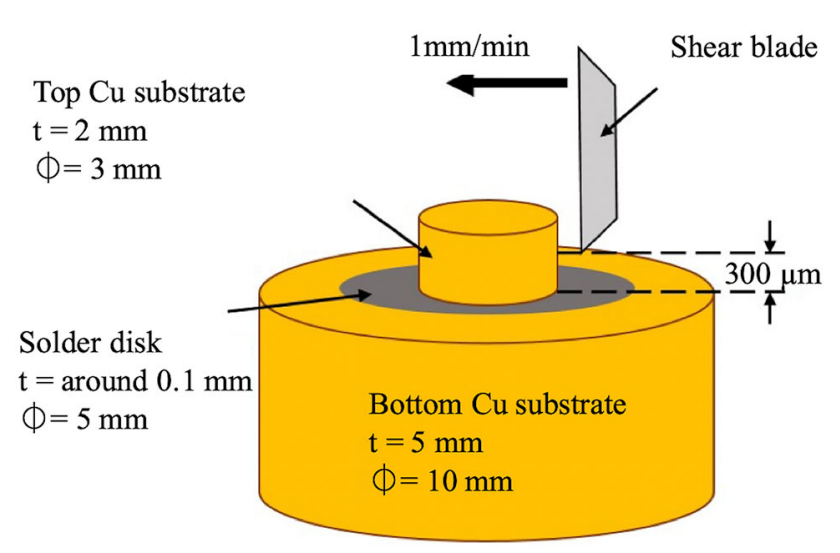

Fig. 3. Schematic illustration of shear test.

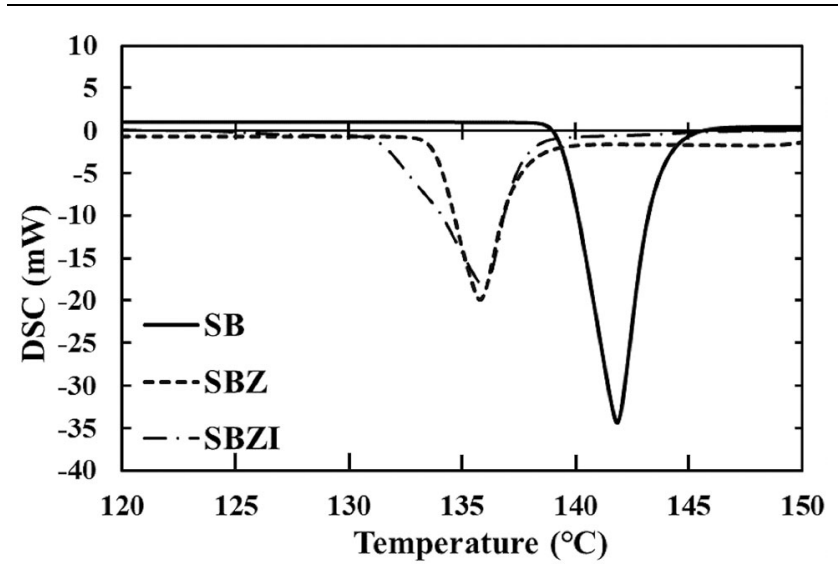

Fig. 4. DSC curves of alloys investigated in this study. contact angles are similar and $<20^{\circ}$, with that for SB being the smallest under the reflow conditions investigated.

\section{Microstructure Near and at Interface of Wettability Test Sample}

The cross-sectional side-view images of the interfaces formed between the alloys and $\mathrm{Cu}$ substrate taken before aging are shown in Fig. 6. The inset images show high-magnification images. Figure $6 \mathrm{a}$ presents the interface between alloy SB and the $\mathrm{Cu}$ substrate, (b) shows the interface between SBZ and $\mathrm{Cu}$ substrate, and (c) displays the interface between SBZI and $\mathrm{Cu}$ substrate. Table III lists the results of an EDS elemental analysis performed at point A, B, and $\mathrm{C}$ in Fig. $6 \mathrm{a}, \mathrm{b}$, and c, respectively. When $\mathrm{Zn}$ and In were added into the Sn-Bi alloy, the microstructure of the alloy as well as the structure of the interface between the alloy and $\mathrm{Cu}$ changed. Near the interface, the SB alloy primarily consisted of a fine, bright-colored $\mathrm{Bi}$ and a fine, dark-colored $\mathrm{Sn}$ phase with a lamellar structure, constituting a eutectic structure. The SBZ and SBZI alloys consisted of a eutectic structure and a Sn phase with small Bi crystals. The SBZ and SBIZ alloys with low Bi contents contained the Sn phase in significantly

Table II. Melting behaviors of investigated alloys as determined by DSC

\begin{tabular}{|c|c|c|}
\hline Alloy & $\underset{\left({ }^{\circ} \mathrm{C}\right)}{\text { Onset }} \underset{\text { temperature }}{T_{S}}$ & $\underset{\left({ }^{\circ} \mathrm{C}\right)}{\text { Offset }} \underset{\text { temperature }}{T_{L}}$ \\
\hline $\mathrm{Sn}-45 \mathrm{Bi}(\mathrm{SB})$ & 137.1 & 144.5 \\
\hline $\begin{array}{l}\text { Sn-45Bi-2.6Zn } \\
\text { (SBZ) }\end{array}$ & 134.1 & 138.1 \\
\hline $\begin{array}{l}\text { Sn-45Bi-2.6Zn- } \\
0.5 \mathrm{In}(\mathrm{SBZI})\end{array}$ & 131.3 & 137.6 \\
\hline
\end{tabular}

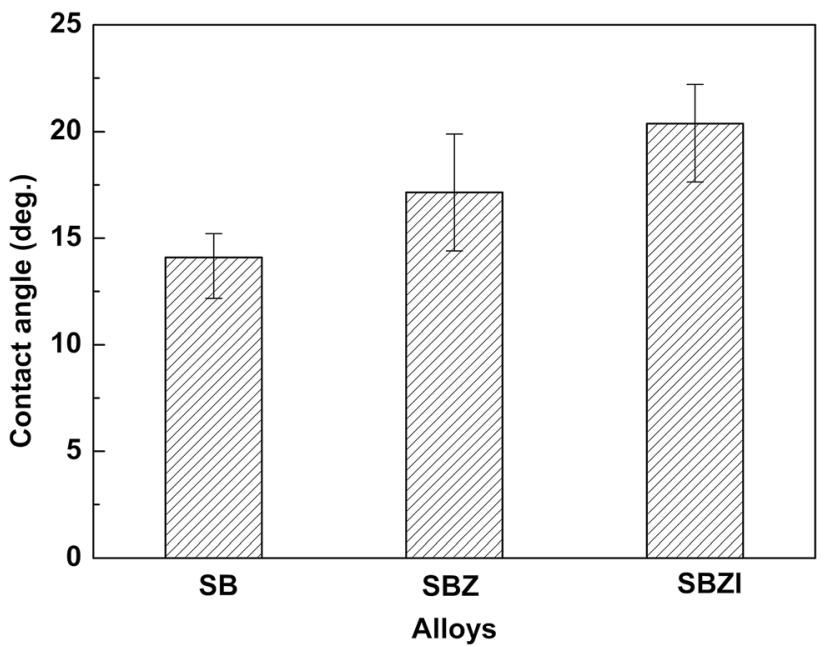

Fig. 5. Measured contact angles of alloys investigated in this study. 

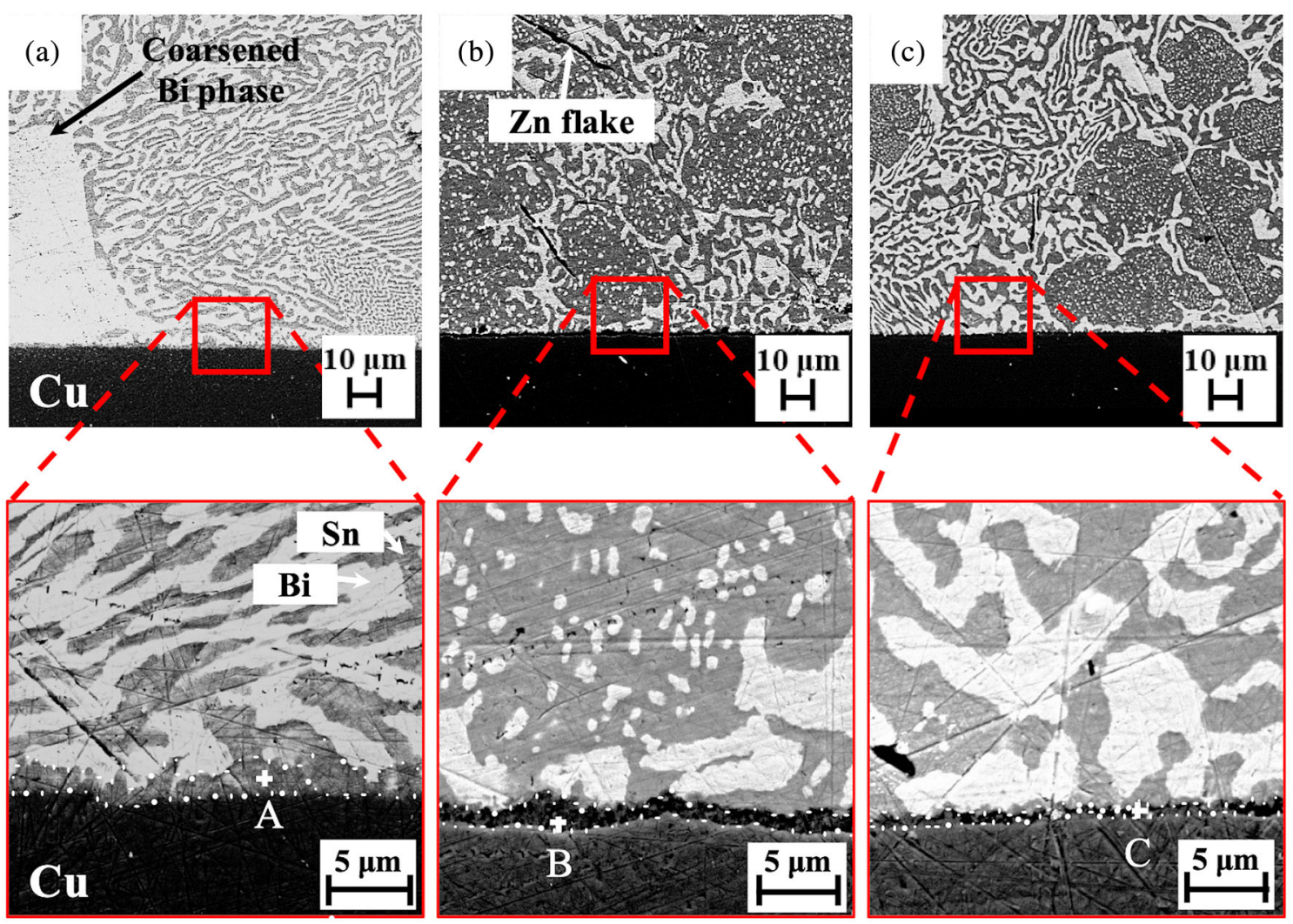

Fig. 6. Cross-sectional SEM images of microstructure at interface before aging: (a) SB, (b) SBZ, and (c) SBZI. Insets show high-magnification images of interface.

Table III. EDS elemental point analysis results for reaction layer shown in Fig. 6

\begin{tabular}{|c|c|c|c|c|c|c|c|}
\hline \multicolumn{2}{|c|}{ Location } & \multicolumn{5}{|c|}{ Composition (at.\%) } & \multirow[b]{2}{*}{ Estimated IMC type } \\
\hline Alloy & Point & Sn & $\mathbf{B i}$ & $\mathbf{Z n}$ & In & $\mathbf{C u}$ & \\
\hline SB & A & 48.93 & 1.54 & - & - & 49.53 & $\mathrm{Cu}_{6} \mathrm{Sn}_{5}$ \\
\hline SBZ & B & 5.04 & 0.21 & 63.50 & - & 31.46 & $\mathrm{Cu}_{5} \mathrm{Zn}_{8}$ \\
\hline SBZI & C & 1.65 & 0.03 & 62.24 & 0.16 & 35.92 & $\mathrm{Cu}_{5} \mathrm{Zn}_{8}$ \\
\hline
\end{tabular}

higher volume fractions than the SB alloy. Moreover, several needle-shaped Zn-phase flakes were distributed within the alloys. These results agree with those of our previous studies. ${ }^{25,28}$ At the $\mathrm{SB} / \mathrm{Cu}$ interface, a thin reaction layer with scallop-like shape and a thickness of approximately $1 \mu \mathrm{m}$ was observed. The EDS results indicated that this layer could be estimated to the IMC $\mathrm{Cu}_{6} \mathrm{Sn}_{5}$. In addition, some large coarsened $\mathrm{Bi}$ phases were observed at the interface. However, $\mathrm{Bi}$ coarsening was not observed in the SBZ and SBZI alloys. Furthermore, at the $\mathrm{SBZ} / \mathrm{Cu}$ and $\mathrm{SBZI} / \mathrm{Cu}$ interfaces, a thin and flat reaction layer with a thickness of approximately 1-2 $\mu \mathrm{m}$ was observed. Based on the EDS results and $\mathrm{Cu}-\mathrm{Zn}$ binary phase diagram, this layer could be estimated to the IMC $\mathrm{Cu}_{5} \mathrm{Zn}_{8}$.
Figure 7 shows cross-sectional SEM images of the interface between the various alloys and the $\mathrm{Cu}$ substrate obtained after aging for $1008 \mathrm{~h}$ in an oil bath at $80{ }^{\circ} \mathrm{C}$. The inserts show high-magnification images. Figure 7 a shows the interface between SB and the $\mathrm{Cu}$ substrate, (b) shows the interface between SBZ and the $\mathrm{Cu}$ substrate, and (c) shows the interface between SBZI and the $\mathrm{Cu}$ substrate. Table IV lists the EDS results for points A, B, and C in Fig. 7a, b, and c, respectively. For all of the alloys, the microstructure near the interface coarsened after aging for $1008 \mathrm{~h}$, as evidenced by the presence of a coarsened Bi phase in the eutectic structure and the increase in the eutectic spacing between the $\mathrm{Bi}$ phases. Conversely, the volume fraction of the $\mathrm{Sn}$ phase was greater in SBZ and SBZI than that in SB. However, large, coarsened $\mathrm{Bi}$ grains were not 

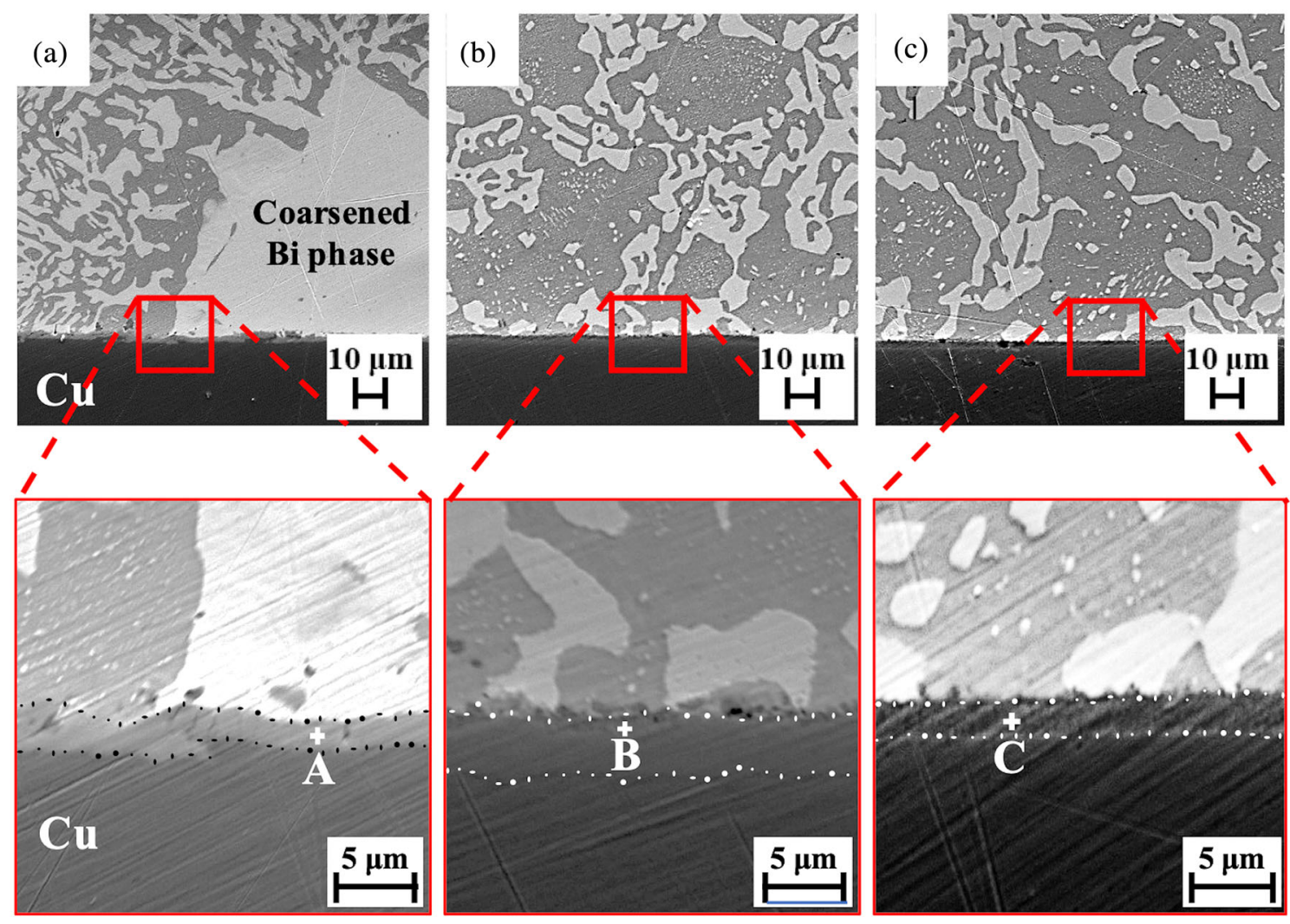

Fig. 7. Cross-sectional SEM images of microstructure at interface after aging for $1008 \mathrm{~h}$ : (a) SB, (b) SBZ, and (c) SBZI. Insets show highmagnification images of interfaces.

Table IV. EDS elemental point analysis results of reaction layer shown in Fig. 7

\begin{tabular}{|c|c|c|c|c|c|c|c|}
\hline \multicolumn{2}{|c|}{ Location } & \multicolumn{5}{|c|}{ Composition (at.\%) } & \multirow[b]{2}{*}{ Estimated IMC type } \\
\hline Alloy & Point & Sn & $\mathbf{B i}$ & $\mathbf{Z n}$ & In & $\mathbf{C u}$ & \\
\hline SB & $\mathrm{A}$ & 37.96 & 0.53 & - & - & 61.52 & $\mathrm{Cu}_{6} \mathrm{Sn}_{5}$ \\
\hline SBZ & $\mathrm{B}$ & 4.98 & 1.02 & 56.51 & - & 37.49 & $\mathrm{Cu}_{5} \mathrm{Zn}_{8}$ \\
\hline SBZI & $\mathrm{C}$ & 0.04 & 0.14 & 59.25 & 0.09 & 40.49 & $\mathrm{Cu}_{5} \mathrm{Zn}_{8}$ \\
\hline
\end{tabular}

observed in SBZ and SBZI even after aging for 1008 $\mathrm{h}$. In addition, in the case of all the joints, the growth of an IMC layer was observed at the interface after aging for $1008 \mathrm{~h}$. At the $\mathrm{SB} / \mathrm{Cu}$ interface, a thin and flat reaction layer with a thickness of approximately $2 \mu \mathrm{m}$ was observed; this layer was probably of the IMC $\mathrm{Cu}_{6} \mathrm{Sn}_{5}$, based on the EDS results listed in Table IV. In addition, a large, coarsened Bi phase could be observed clearly at the interface, but there was no sign of Bi coarsening at the interface of the SBZ and SBZI alloys. Furthermore, at the SBZ/Cu and SBZI/Cu interfaces, flat reaction layers with a thickness of approximately 2$3 \mu \mathrm{m}$ were observed, and these layers were probably of the IMC $\mathrm{Cu}_{5} \mathrm{Zn}_{8}$ as per the EDS results and the $\mathrm{Cu}-\mathrm{Zn}$ binary phase diagram. Based on the cross- sectional images of the various joints, it can be concluded that the SBZ and SBZI joints contained lower volume fraction of $\mathrm{Bi}$, resulting in a lower possibility of $\mathrm{Bi}$ coarsening after aging. In addition, the inclusion of In may be effective in preventing the coarsening of the Bi-rich phase and growth of the IMC layer at the interface, as observed in our previous study. ${ }^{25}$ Moreover, it also suggests that SBZI exhibits the most promising microstructure among all the joints examined in this study.

\section{Shear Strength of the Jointed Sample}

The results of the shear tests for SB, SBZ, and SBZI alloy joints formed using $\mathrm{Cu}$ disks before aging are shown in Fig. 8. The shear strengths of the SBZ 
and SBZI joints were lower than that of the SB joint. The average shear strengths of the SBZ and SBZI joints were similar at approximately $50 \mathrm{MPa}$. Figure 9 shows SEM images of fracture surfaces of the bottom substrate of the various $\mathrm{Cu} / \mathrm{Cu}$ joints obtained before aging. The black arrows on the top images indicate the direction of shearing. The SBZ and SBZI joints contained more voids than the SB joint. Calculating the void ratio confirmed that the

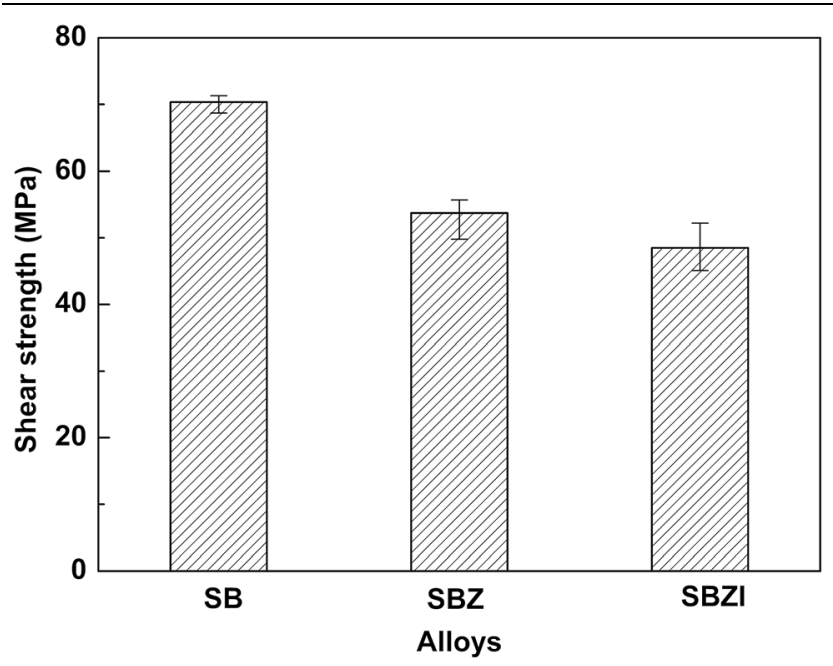

Fig. 8. Shear test results for $\mathrm{Cu} / \mathrm{Cu}$ joints before aging. void ratio of SB was the lowest, which was around $8.6 \%$. As for the SBZ and SBZI, the void ratios were similar to each other at $18.4 \%$ and $20.2 \%$, respectively. The difference in the void ratio may explained in that the shear strength of SB was higher than those of SBZ and SBZI before the aging test. In addition, for all the alloys, brittle fracturing was observed. The SB alloy showed cleavage failure, as can be observed from the high-magnification image in Fig. 9a. The formation of the coarsened $\mathrm{Bi}$ phase at the interface was the main cause of the cleavage failure. In addition, the shear strengths of the SBZ and SBZI joints were lower than that of the SB joint probably because the former contained more large voids than the latter. This suggests that the flux used in this study is not suitable for the SBZ and SBZI alloys developed by our group.

Figure 10 shows the effect of the aging time at 80 ${ }^{\circ} \mathrm{C}$ on the shear strength of the SB, SBZ, and SBZI alloy joints formed using the $\mathrm{Cu}$ disks. Only the SB alloy joint exhibited a degradation in its shear strength during aging, with its shear strength decreasing by $15 \%$. In contrast, the shear strengths of the SBZ and SBZI joints remained unchanged at approximately $50 \mathrm{MPa}$ after $1008 \mathrm{~h}$. Thus, similar to the microstructural analysis results, this finding may also be attributable to significantly lower $\mathrm{Bi}$ contents of SBZ and SBZI than that of SB because of the decreased volume fraction of the Bi phase. This, in turn, resulted in a decrease in the possibility of the formation of coarsened $\mathrm{Bi}$ after aging. Overall, these results suggest that the SBZI alloy
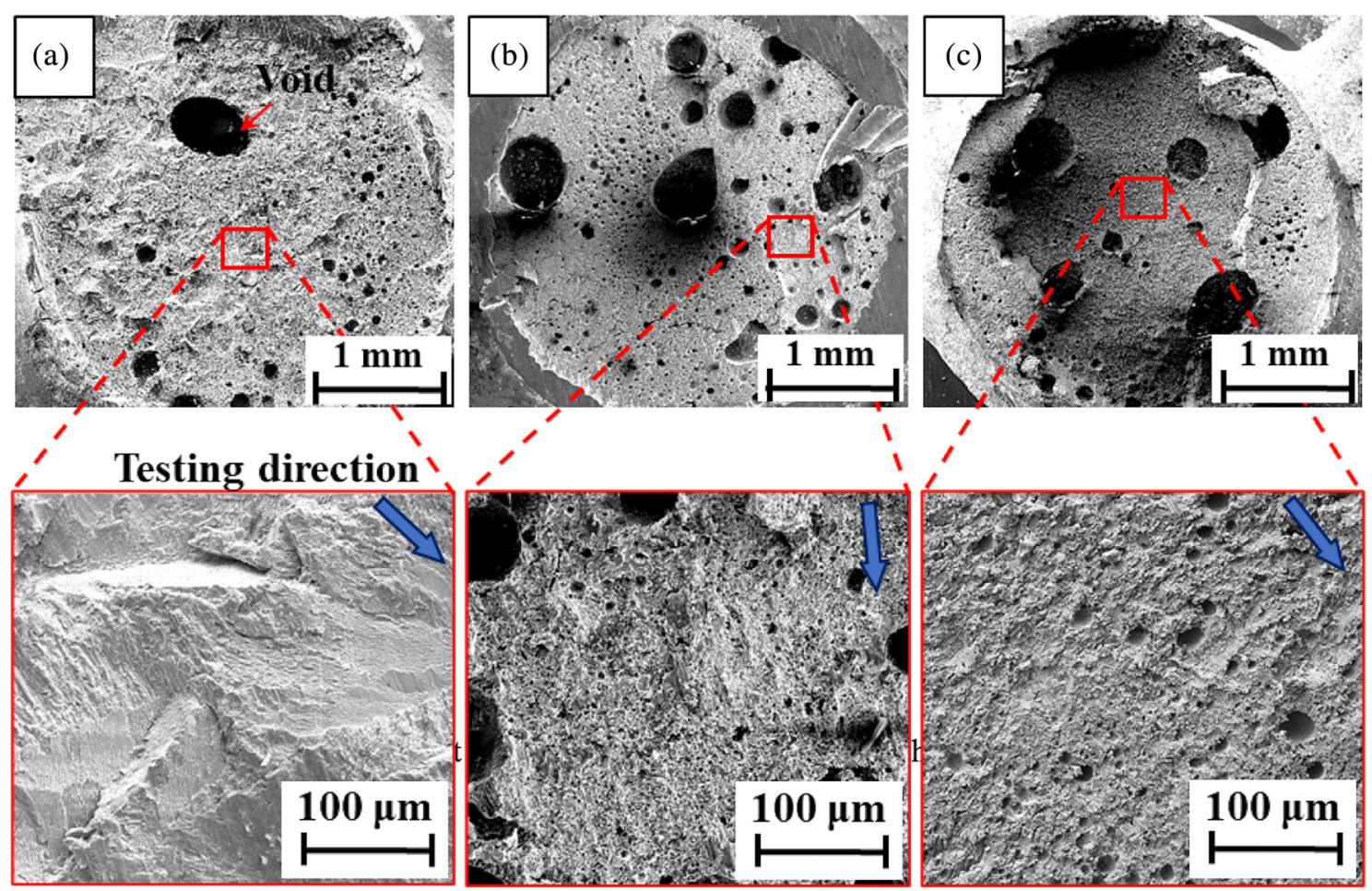

Fig. 9. SEM images of fracture surfaces of $\mathrm{Cu} / \mathrm{Cu}$ joints by shear test before aging: (a) SB, (b) SBZ, and (c) SBZI. Insets show high-magnification images of selected areas. 


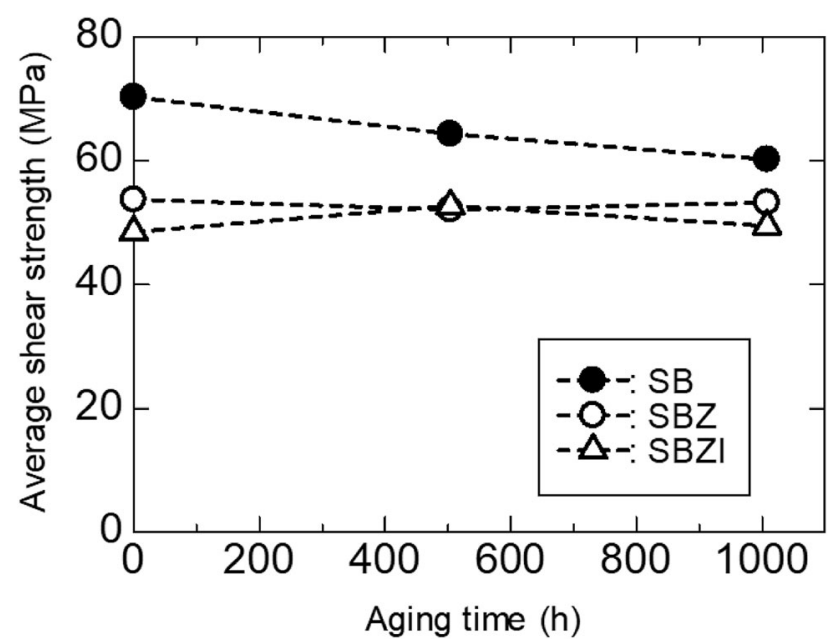

Fig. 10. Effect of aging time on shear strengths of $\mathrm{Cu} / \mathrm{Cu}$ joints.

demonstrates the highest long-term reliability among all the joints examined in this study.

\section{CONCLUSION}

To elucidate the effects of the addition of $\mathrm{Zn}$ and In to the $\mathrm{Sn}-45 \mathrm{Bi}$ alloy on the interfaces and shear strengths of $\mathrm{Cu} / \mathrm{Cu}$ joints before and after aging, $\mathrm{Cu} /$ $\mathrm{Cu}$ joints were formed using $\mathrm{Sn}-45 \mathrm{Bi}$ alloy containing both $\mathrm{Zn}$ and In and investigated in depth. In particular, eutectic SB, SBZ, and SBZI alloys were prepared. The contact angles of the three alloys on the $\mathrm{Cu}$ substrate were similar and $<20^{\circ}$. At the $\mathrm{SBZ} / \mathrm{Cu}$ and $\mathrm{SBZI} / \mathrm{Cu}$ interfaces, thin and flat reaction layers were observed, and these layers were estimated to the IMC $\mathrm{Cu}_{5} \mathrm{Zn}_{8}$ : this was the case both before and after aging. Moreover, Bi coarsening was not observed either near or at the interfaces of the SBZ and SBZI joints. The shear strength of the SBZ and SBZI joints remained unchanged at approximately $50 \mathrm{MPa}$ after aging for $1008 \mathrm{~h}$. The SBZI alloy demonstrated the highest long-term reliability among all the joints examined in this study.

\section{ACKNOWLEDGEMENTS}

This work was financially supported by Project to Create Research and Educational Hubs for Innovative Manufacturing in Asia, Osaka University of Special Budget Project by the Ministry of Education, Culture, Sports, Science and Technology.

\section{CONFLICT OF INTEREST}

The authors declare that they have no conflict of interest.

\section{OPEN ACCESS}

This article is licensed under a Creative Commons Attribution 4.0 International License, which permits use, sharing, adaptation, distribution and reproduction in any medium or format, as long as you give appropriate credit to the original author(s) and the source, provide a link to the Creative Commons licence, and indicate if changes were made. The images or other third party material in this article are included in the article's Creative Commons licence, unless indicated otherwise in a credit line to the material. If material is not included in the article's Creative Commons licence and your intended use is not permitted by statutory regulation or exceeds the permitted use, you will need to obtain permission directly from the copyright holder. To view a copy of this licence, visit $h$ ttp://creativecommons.org/licenses/by/4.0/.

\section{REFERENCES}

1. M. Abtew, and G. Selvaduray, Mater. Sci. Eng. R Rep. 27, 95 (2000).

2. S. Cheng, C.-M. Huang, and M. Pecht, Microelectron. Reliab. 75, 77 (2017).

3. L. Zhang, C.-W. He, Y.-H. Guo, J.-G. Han, Y.-W. Zhang, and X.-Y. Wnag, Microelectron. Reliab. 52, 559 (2012).

4. H. Matsui, Y. Takeda, and S. Tokito, Organic Electron. 75, 105432 (2019).

5. S. Pradhan, A.K. Brooks, and V.K. Yadavalli, Mater. Today Biol. 7, 100065 (2020).

6. T.H. Im, J.H. Lee, H.S. Wang, S.H. Sung, Y.B. Kim, Y. Rho, C.P. Grigoropoulos, J.H. Park, and K.J Lee, Materials Today (2021). Article in Press.

7. G. Ren, I.J. Wilding, and M.N. Collins, J. Alloys Compd. 665, 251 (2016).

8. H.R. Kotadia, P.D. Howes, and S.H. Mannan, Microelectron. Reliab. 54, 1253 (2014).

9. M.F. Mohd Nazeri, M.Z. Yahaya, A. Gursel, F. Cheani, M.N. Masri, and A.A. Mohamad, Solder. Sur. Mt. Technol. 31, 52 (2019).

10. F. Wang, H. Chen, Y. Huang, L. Liu, and Z. Zhang, J. Mater. Sci. Mater. Electron. 30, 3222 (2019).

11. L.E. Felton, C.H. Raeder, and D.B. Knorr, JOM 45, 28 (1993).

12. C.H. Raeder, L.E. Felton, V.A. Tanzi, and D.B. Knorr, J. Electron. Mater. 23, 611 (1994).

13. L. Shen, P. Septiwerdani, and Z. Chen, Mater. Sci. Eng. A 558, 253 (2012).

14. W.K. Choi, S.W. Yoon, and H.M. Lee, Mater. Trans. 42, 783 (2001).

15. I.E. Anderson, J.C. Foley, B.A. Cook, J. Harringa, R.L. Terpstra, and O. Unal, J. Electron. Mater. 30, 1050 (2001).

16. H. Nishikawa, A. Komatsu, and T. Takemoto, J. Electron. Mater. 36, 1137 (2007).

17. L. Xu, L. Wang, H. Jing, X. Liu, J. Wei, and Y. Han, J. Alloys Compd. 650, 475 (2015).

18. M. Sobhy, Mater. Sci. Eng. A 610, 237 (2014).

19. Y. Tang, G.Y. Li, and Y.C. Pan, Mater. Des. 55, 574 (2014).

20. F. Hou, Z. Jin, D. L. Han, K. Zhang, and H. Nishikawa, Mater. Des. 210, 110038 (2021).

21. M. Mccormack, H.S. Chen, G.W. Kammlott, and S. Jin, J. Electron. Mater. 26, 954 (1997).

22. X. Chen, F. Xue, J. Zhou, and Y. Yao, J. Alloys Compd. 633, 377 (2015).

23. X. Li, Y. Ma, W. Zhou, and P. Wu, Mater. Sci. Eng. A 684, 328 (2017).

24. O. Mokhtari, and H. Nishikawa, J. Electron. Mater. 43, 4158 (2014).

25. O. Mokhtari, and H. Nishikawa, Mater. Sci. Eng. A 651, 831 (2016).

26. S. Zhou, O. Mokhtari, M.G. Rafique, V.C. Shunmugasamy, B. Mansoor, and H. Nishikawa, J. Alloys Compd. 765, 1243 (2018). 
27. S. Zhou, C. Yang, Y. Shen, S. Lin, and H. Nishikawa, Materialia, 6, 100300 (2019).

28. Y. Hirata, C. Yang, S. Lin, and H. Nishikawa, Mater. Sci. Eng. A, 813, 141131 (2021).
Publisher's Note Springer Nature remains neutral with regard to jurisdictional claims in published maps and institutional affiliations. 